\title{
Application and Preparation of Chitosan Electrochemical Sensor
}

\author{
Funeng TAN
}

Chemical and engineering institute, Wenshan University, Wenshan 663000, Yunnan, China

Keywords: chitosan; electrochemical sensor; preparation; application

\begin{abstract}
During the last decade, the sensors based on chitosan had been an active research topic due to its great practical value. The sensors had showed excellent superiority, low cost, ease of fabrication, fast response time and nice repeatability. This review discusses the preparation and application of sensors based on in metallic ion detection, non-metallic ions detection, organic detection and biosensors are reviewed, and future applications are prospected.
\end{abstract}

\section{Introduction}

Chitosan (CS), a non-acetylated orpartially deacetylated chitin can be found in the fungal cell wall and the exoskeletons of lots of arthropods such as crabs and shrimps. It had been widely employed as a drug delivery system, wound dressing, anticoagulants, and scaffolds for tissue engineering $^{[1]}$. Chitosan have various applications as a stabilizing agent and dispersant due to film-forming ability, biocompatibility, good adhesion, high mechanical strength, high permeability towards water, susceptibility to chemical modification and cost-effectiveness for enzyme immobilization. Moreover, amino and hydroxyl groups of chitosan provide a hydrophilic environment compatible with the biomolecules ${ }^{[2-4]}$.

In the recent years, with the active research of sensor on analytical chemistry, chitosan has been developed into membrane material of electrode for preparation of chemical sensors and biosensors $^{[5,6]}$. These sensors based on can effectively determine not only metal ions ${ }^{[7]}$, non-metallic ions $^{[8]}$, but also various organics ${ }^{[9]}$. chitosan has also been seleeted as immobilization material of enzyme for preparation of enzyme biosensor ${ }^{[10,11]}$. This review discussed preparation and application of sensor base on chitosan.

\section{Preparation of chitosan electrochemical sensor}

\section{Method of covalent immobilization}

The method contains two-step, firstly, the surface of glass carbon electrode(GCE) was pretreated and carboxyl groups were introduced. Secondly, organic synthesis was conducted on the surface of electrode and the electrode was modified with chitosan. Liu ${ }^{[12]}$ prepared tyrosinase-chitosan composite film-modified glassy carbon electrode by using method of covalent immobilization, and neurotransmitters metabolite of 3,4-dihydroxyphenylacetic acid was detected at the sensor. $\mathrm{Li}$ et $\mathrm{al}^{[13]}$ reported glassy carbon electrode was modified with chitosan by using method of covalent-band reaction. The anodic stripping voltammetric behavior of $\mathrm{NO}_{2}^{-}$at this sensor was examined, and amounts of $\mathrm{NO}_{2}{ }^{-}$in the rain water and lake water were determined with satisfactory results.

\section{Method of blend}

The electrode was modified by using electrode material mixture of chitosan, as modified carbon paste electrode, which was prepared by mixing of chitosan, graphite powder and paraffin. Feng ${ }^{[14]}$ worked on preparing a chistosan-carbon paste modified electrode by mixing of chistosan, graphite powder, and paraffine at the appropriate ratios. The anodic stripping voltammetric behavior of $\mathrm{I}^{-}$at this sensor was examined, and relative mechanism was discussed. This sensor was applied to determine $\mathrm{I}^{-}$in iodine with satisfactory results.

\section{Method of painting}

Chitosan solution droplets were coated the surface of electrode and formed a thin film. There are two ways of painting electrode, dip coating and expansion. Jiang ${ }^{[15]}$ prepared a novel 
chitosan-carboxylic multiwall carbon nanotube modified glassy carbon electrode by using method of painting. The electrochemistry behavior and diffusion performance of $\mathrm{NO}_{2}{ }^{-}$on this modified electrode was investigated. Ding and colleagues ${ }^{[16]}$ reported a glassy carbon electrode was modified by pipetting a aliquot solution of the material of chitosan and activated cabon-nanotube onto the electrode surface. The cyclic voltammetry and differential pulse voltammetry behavior of $\beta$-nicotinamide adenine dinucleotide at this sensor was examined.

\section{Method of electrodeposition}

This method was reported as the chitosan was deposited on the surface of electrode firmly via electrochemical method. Wang ${ }^{[17]}$ prepared chitosan/prussian blue films of surface of electrode via electrodeposition, which was carried out by potential controlled electrolysis. This composite film was characterized by Fourier transform infrared and optical microscopy and show that the film was more massive and more spatial structural. The electrochemical behavior of $\mathrm{H}_{2} \mathrm{O}_{2}$ on chitosan/prussian modified gold electrode was investigated. This sensor display a high sensitivity and selectivity long-term stability, good reproducibility of $\mathrm{H}_{2} \mathrm{O}_{2}$.

\section{Application of chitosan electrochemical sensor}

\section{Determination of metal ions}

A great numbers of studies have recently been focused on detection of metal ions in environmental and food samples. Those methods that used chemically modified electrodes by chitosan are active topics. The amino group on the chitosan is responsible for the chelation of many metal cation $\mathrm{Cu}^{2+} 、 \mathrm{Fe}^{3+} 、 \mathrm{~Pb}^{2+} 、 \mathrm{Hg}^{2+} 、 \mathrm{Cd}^{2+} 、 \mathrm{Ni}^{2+} 、 \mathrm{Zn}^{2+} 、 \mathrm{Au}^{3+} 、 \mathrm{Ag}^{+[18-20]}$. In resent years, Chitosan has been developed into membrane material of electrode for preparation of chemical sensors and use to the detection of metalions.

Zhang ${ }^{[21]}$ worked on preparing a novel of chitosan modified glass carbon electrode by the method of covalent-bond reaction. The anodic stripping voltammetric behavior of $\mathrm{Sn}^{2+}$ at this sensor was examined, the mechanism and experiment condition was discussed. The result of anodic stripping voltammetric showed that sensitivity of modified glass carbon electrode for $\mathrm{Sn}^{2+}$ raises around tenfold. This sensor has been applied to the electrochemical determination of $\mathrm{Sn}^{2+}$ in canned food, with satisfactory results.

$\mathrm{Liu}^{[22,23]}$ prepared cyanoethylchitosan via cyanoethyl group was introduced to chitosan and used cyanoethylchitosan to modify the glass carbon electrode through covalent bond reaction. The modified electrode has higher adsorptive capacity and better selectivity for $\mathrm{Cu}^{2+}$.

$\mathrm{Lu}^{[24]}$ reported a novel of preconcentration and cathodic stripping voltammetric method was developed for the determination of total Fe by a chitosan modified glassy carbon electrode. this sensor can be used to determinate total $\mathrm{Fe}$ tap water and mineral water directly, because $\mathrm{C}_{2} \mathrm{O}_{4}{ }^{2-}$ was used as a complex agent and reductant. The complex of $\mathrm{Fe}\left(\mathrm{C}_{2} \mathrm{O}_{4}\right)_{3}{ }^{3-}$ is unstable to light, and turns to $\mathrm{Fe}\left(\mathrm{C}_{2} \mathrm{O}_{4}\right)_{3}{ }^{4-}$, as $\mathrm{C}_{2} \mathrm{O}_{4}{ }^{2-}$ makes $\mathrm{Fe}^{3+}$ turn to $\mathrm{Fe}^{2+}$.

Ye and colleagues ${ }^{[25-28]}$ worked on preparing a series of sensors with chitosan and using these sensors to determine $\mathrm{Ag}^{+}, \mathrm{Au}^{3+}, \mathrm{Pt}^{4+}, \mathrm{Pd}^{2+}$ by anodic stripping voltammetry, discussing the mechanism of determination.

\section{Determination of non-metal ions}

The sensors based on have been developed for the determination of non-metal ions due to the excellent adsorption of chitosan.

$\mathrm{Liu}^{[29]}$ prepared a new chitosan modified platinum electrode. This sensor had been applied to the determination of $\mathrm{I}^{-}$by Semi-differential voltammetry, and consistent results were obtained as compared with the indirect flame atomic absorption spectrophotometer, giving a relative deviation of about $5 \%$.

$\mathrm{Xu}^{[30,31]}$ prepared a new chitosan derivatives by reaction of schiff base in water. A glassy carbon electrode was modified by this chitosan derivatives. The methods have been applied to determining $\mathrm{NO}_{2}{ }^{-}$in water.

Zeng $^{[32]}$ reported a glassy carbon electrode was modified with chitosan by drop coating method. 
This sensor was developed for the determination of $\mathrm{Br}^{-}$and $\mathrm{I}^{-}$by stripping voltammetry. Chitosan sensors has been also developed for the determination of $\mathrm{Br}^{-[33]}, \mathrm{SCN}^{-[34]}$.

\section{Determination of organic}

The sensors based on can effectively determine not only metal ions, non-metallic ions, but also various organics. Chen ${ }^{[35]}$ prepared graphite disc electrode modified with chitosan by drop-coating method. This sensor can determine L-ascorbic acid by method of semi differential voltammetry. Jiang $^{[36]}$ et al reported a modified electrode based on a chitosan multiwall carbon nanotube coated glassy carbon electrode is described, which exhibits an excellent sensitivity to determine dopamine and ascorbic acid simultaneously. Yang and $\mathrm{Wei}^{\left[{ }^{[3]}\right.}$ reported a $\beta$-cyclodextrin multiwalled carbon nanotubes/chitosan modified electrode was prepared by layers by layer self assembly technique. The electrochemical behavior of dopamine at the modified electrode was also studied.

$\mathrm{Liu}^{[38]}$ prepared a novel of glass carbon electrode was modified with chitosan by drop coating method. The electron mediator hexacyanoferrate was fixed in the film based on electrostatic interaction between the protonated acetyl amide groups of the chitosan in low $\mathrm{pH}$ solution and hexacyanoferrate anions. The oxidation of ascorbic acid at the electrode was investigated.

Zhao $^{[39.40]}$ reported electrochemical behavior of $\mathrm{Fe}(\mathrm{EDTA})^{-}$at the chitosan modified glass carbon electrode(GCE) by a convolution valtammetry method and studied related mechanism. He considered that Fe (EDTA) ${ }^{-}$can be adsorbed into the positively charged chitosan membrane assembled on GCE. Finally, the result was consistent with that from high performance liquid chromatography method.

$\mathrm{Liu}^{[41]}$ prepared a novel of schiff base chitosan and used it to modify glassy carbon electrode The electrode can be used for the determination of trace amounts of hydroquinone with differential pulse voltammetry.

Wang ${ }^{[42]}$ reported a novel ordered mesoporous carbons modefied electrode was prepared by using the chitosan as dispersant. The cyclic vohammetric behavior of uric acid was examined at this sensor. Chitosan modified electrode has been developed for the medical sensitive sensor ${ }^{[43]}$.

\section{Immobilization of enzymes}

The immobilization of enzymes in the fabrication of biosensors has been an active research topic in sensor design. In the recent years, chitosan usually used as a matrix to immobilize biomolecules to construct biosensors such as enzyme electrodes. Chitosan molecules contain lots of amino groups, which have high affinity for biomacromolecule ${ }^{[44,45]}$. So the chitosan adsorbed on the surface of the electrode provides an efficient matrix for the immobilization of enzyme. Chitosan was develop materials of prepared porous membrane ${ }^{[46]}$ and porous microparticles ${ }^{[47-49]}$, which can conducive to immobilization of enzyme.

The methods of immobilizing enzymes by chitosan include adsorption, crosslinking, self-assembly method and sol-gel method.

\section{1) Immobilizing enzymes by adsorption}

The enzyme was adsorbed on the chitosan via hydrogen bond, hydrophobic bond, and electrostatic interaction. This method can maintain the activity of enzyme. Lei ${ }^{[50]}$ prepared an enzyme electrode has been described based on the effective adsorption of horseradish peroxidase (HRP) to a nano-scaled particulate gold (nano-Au) monolayer modified chitosan-entrapped carbon paste electrode (CCPE) (Fig 2). The high affinity of chitosan entrapped in CCPE for nano-Au associated with its amino groups has been utilized to realize the use of nano-Au as an intermediator to retain high bioactivity of the enzyme. This sensor can determine $\mathrm{H}_{2} \mathrm{O}_{2}$ by using an amperometric method.

$\mathrm{Cao}^{[51]}$ reported preparation of a novel schistosoma japonicum immunosensor based on aggregation of chitosan and activated alginate. activated alginate and antibody is aggregated on the surface of the electrode by electrostatic adsorption. This sensor was applied to the determination of schistosoma japonicum antigen in rabbit serum with satisfactory results.

\section{2) Immobilizing enzymes by crosslinking}

The formation of network structure between enzyme molecules and chitosan molecules was caused by the cross-linking agent. The method of enzyme of immobilization has been widely 
applied in the field of the preparation of sensor.

$\mathrm{Li}^{[52,53]}$ worked on the preparation of a novel of choline biosensor based on the chitosan film immobilized horseradish peroxidase and choline oxidase. The result showed that both sensitivity and selectivity of the biosensor were excellent.

\section{3) Immobilizing enzymes by self-assembly}

Self-assembly method including the spontaneous adsorption of chitosan molecules in the heterogeneous interface via chemical bonds. Preparation of biosensor by using self-assembly method has been an active research topic in sensor design ${ }^{[55]}$.

With the modified electrode by self-assembly method, some biosensors were prepared to determining paraoxon ${ }^{[56]}$, sterigmatocystin ${ }^{[57]}$.

\section{4) Immobilizing enzymes by sol-gel method}

The preparation of composite film by using method of sol-gel has various desirable advantages, excellent stability, high mechanical strength and maintaining the activity of enzyme ${ }^{[58]}$. Tan has done a series of work in this field, he ${ }^{[59]}$ prepared a novel of organic-inorganic hybrid film was prepared by sol-gel with chitosan and tetraethyl orthosilicate. The hybrid film was used to immobilize horseradish peroxidase (HRP) on the surface of a gold electrode to preparing a $\mathrm{H}_{2} \mathrm{O}_{2}$ biosensor. This sensor has high sensitivity and selectivity of $\mathrm{H}_{2} \mathrm{O}_{2}$ due to hybrid film provides a microenvironment friendly for enzyme loading and for the enzymes to retain their activity to great extent.

\section{Conclusions and outlook}

In the recent years, with the development of works on chitosan, large of chitosan and its derivatives were applied to the preparation of sensor. It has been an active research topic in the field of analytical chemistry. These sensors have a lot of advantages, low cost, ease of fabrication, fast response time and nice repeatability. However, there are a number of critical issues that require addressing, including reliable manufacturing methods, excellent ability of anti-jamming, simultaneous determination of multicomponent, nice separative ability. These key issues to be resolved by researchers. With the deep study on sensors based on, in the near future, the sensors based on will potentially be applied to multicomponent analysis in environmental control, the chemical industry and pharmaceutical detection.

\section{References}

[1] Jiang T D. Chitin. Beijing: Chemical Industry Press, 2003: 8-20

[2] Seunglee K, Park J. Langmuir. 2003, 19(10): 188-193

[3] Ma N, Wang Q, Sun S L, Wang A Q. Progress in Chemistry. 2004, 16(4): 643—653

[4] Kumar M. Reactive \& Functional Polymers. 2000, 46(1): 1-27

[5] Tan S Y, Wang Y T, Tang Y R. Chinese Journal of Environmental Science. 1999, 20(3): 60

[6] Wang M L, Huang J Q, Qian S H, Wang Y T, Jiang J S. Chinese Journal of Analytical Chemistry. 1997, 25(8): 893

[7] Oshita K, Oshima M, Gao Y H, Lee K H, Motomizu S. Analttica Chimica Acta. 2003, 480(2): 239-249

[8] Huang J M, Jin X R. Chinese Journal of Chromatography, 1993, 11(2): 113-114

[9] Ng L T, Guthrie J T, Yuan Y J, Zha H J. Journal of Applied Polymer Science. 2000, 79(3): $466-472$

[10] Zhang M G, Gorski W. Anal.Chem. 2004, 76(13): 5045—5050

[11] Liu A H, Honma I, Zhou H S. Biosensors and Bioelectronics. 2005, 21(5): 809—816 
[12] Li J, Xu J R, Sun X Y. Chinese Journal of Analytical Chemistry. 2002, 30(2): 206-209

[13] Feng J J, Zhao G, Xu J J, Chen H Y. Analytical Biochemistry. 2005, 342 (2): 280—286

[14] Feng H, Zhou G Z, Li Y H, Sun Y X. Journal of Hunan University of Arts and Science(Natural Science Edition). 2008, 20(1): 49—51

[15] Jiang Y L, Liu L, Niu J L, Liu J T. Advances in Fine Petrochemicals. 2009, 10(6): 47—50

[16] Ding Z H, Kang T F, Hao Y C, Zhang Y. Chemical Research and Application. 2008, 20(4): $374-377$

[17] Wang X Y, Deng K J, Tu Y F. Chinese Journal of Analytical Chemistry. 2008, 36(5): 632-636

[18] Wang Y T, Liu Y H, Zhang S Q. Journal of Functional Polymers. 2002, 15(l): 107-114

[19] Guibal E, Sweenv N V, Vincent T, Tobin J M. Reactive \& Functional Polymers. 2002, 50(2): 149-163

[20] Muzzarelli R A, Tubertini.Q. Talanta. 1969, 16(12): 1571-1577

[21] Zhang M N, Chen D F, Liu B, Xu J R. Journal of Huaqiao University (Natural Science). 2004, 25(4): 383-386

[22] Xu J R, Liu B. Analyst. 1994, 119(7): 1599—1601

[23] Liu B, Sun X Y, Xu J R. Chinese Journal of Applied Chemistry. 2003, 2(10): 963-967

[24] Lu G H, Yao X,Wu X G, Zhan T. Microchemical Journal. 2001, 69(1): 81—87

[25] Yang Q H, Ye X Z, Wang H. Analytical Laboratory. 1998, 17(6): 5-11

[26] Wang Y, Ye X Z, Xu Z H, Li N Q. Chemical Research in Chinese Universities. 1996, 17(9): $1367-1371$

[27] Wang Y, Ye X Z, Li N Q. Acta Scientiarum Naturalium Universitatis Pekinensis. 1996, 32(4), 408-411

[28] Yang Q H, Ye X Z, Hong Z C. Physical Testing and Chemical Analysis Partb Chemical Analgsis. 2000, 36(4): 161-165

[29] Liu W L, Wu Q S, Ding Y P. Physical Testing and Chemical Analysis Partb Chemical Analgsis. 2004, 40 (3): 145-147

[30] Jiang L Y, Wang R X, Li X M, Jiang L P, Lu G H. Electrochemistry Communications.2005, 7(6): 597-601

[31] Xu Z L, Zhang J M, Liu S J, Peng D F. Journal of East China Institute of Technology. 2007, 30 (3): $283-286$

[32] Zeng Y, Wang L R, Li Y L, Lu G H. Journal of Wuhan Institute of Chemical Technology. 2005, 27 (2): 7-9

[33] Yao X, Lu G H, Wu X G, Zhan T. Electroanalysis. 2001, 13(11): 923—926

[34] Lu G H, Yao X, Zhou X C, Long D W. Chemical Research in Chinese Universities. 2002, 18 (3): $316-320$

[35] Chen G, Zhang J X, Zhang X. Chinese Journal of Analytical Chemistry. 2000, 28(10): 1220-1223

[36] Jiang L Y, Liu C Y, Jiang L P, Peng Z, Lu G H. Analytical Sciences. 2004, 20(7): 1055—1060

[37] Yang H C, Wei W Z. Analytical Laboratory. 2009, 28(9): 5—8

[38] Liu H Y, Wang Y L, Zhang G R, Analytical Laboratory. 2003, 22 (1): 5-8 
[39] Zhao C Z, Guo X, Hao C X, Pan Y Z, Su Y, Sun L C. Analytical Laboratory. 2003, 22 (3): $38-40$

[40] Zhao C Z, Egashira N, Kurauchi , Ohga K. Electrochim Acta. 1998, 43(14): 2167—2169

[41] Liu B, Sun X Y, Xu J R. Chinese Journal of Analytical Chemistry. 2003, 31(9): 1048-1052

[42] Wang X X, Chen Y L, Miao Q, Jia Y P. Journal of Analytical Science. 2009, 25(2): 189—192

[43] Li X W, Tian W H, Wu H L, Yang B L. Journal of Weinan Teachers College. 2003, 18(2): $38-40$

[44] Thierry B, Winnik F M, Merhi Y. Biomacromolecules. 2003, 4(6): 1564-1571

[45] Richert L, Lacalle P, Payan E, Shu Z X, Prestwich D G, Stoltz F G. Langmuir. 2004, 20(2): 448-458

[46] CoCC, Wang Y C, Ho C C. J Am. Chem. Soc. 2005, 127(6): 1598-1599

[47] Jiang L F, Zhang S X, Liu H. Chemical World. 1999, 72(12): 638—641

[48] Adachi T, Wakita M, Hashimoto M, Ihara H, Hirayama C. Polymer Journal. 1999, 31(4): $319-323$

[49] Kawamura Y, Yoshida H, Asai S, Tanibe H. Water Science And Technology. 1997, 35(7): 97-105

[50] Lei C X , Hu S Q , Shen G L, Yu R Q. Talanta. 2003, 59 (5): 981—988

[51] Cao X, Hu S Q, Sheng G L, Yu R Q. Chemical Research In Chinese Universities. 2003, 24 (8): $1377-1380$

[52] Li C X, Yang M H, Sheng G L, Yu R Q. Chinese Journal of Analytical Chemistry. 2005, 33(1): 9-12.

[53] Wang G , Xu J J , Chen H Y, Lu Z H. Biosensors and Bioelectronics. 2003, 18 (4): 335—343

[54] Zhu A P, Wang G, Cheng D M, Sheng J. Journal of Functional Materials. 2002, 33 (3): $344-346$

[55] Dong S J, Che G L, Xie Y W. Chemically Modified Electrodes. Beijing: Science Press, 1995 : $571-579$

[57] Constantine C A, Mello S V, Dupont A, Cao X H, Santos D, Oliveira O N, Strixino F T, Pereira E C, Cheng T C, Defrank J J, Leblanc R M. J Am. Chem. Soc. 2003, 125(7): 1805 -1809

[58] Chen J H, Li S C, Yao D S, Liu D L. Chinese Journal of Biotechnology. 2009, 25(12): 2029-2035

[59] Miao Y, Tan S N. Analytica Chimica Acta. 2001, 437(1): 87-93.

[60] Tan X C, Huang T T, Xu J J, Luo L J, Zhou X Y, Cai P X. Journal of Instrumental Analysis. 2004, 23 (4): 9-12 